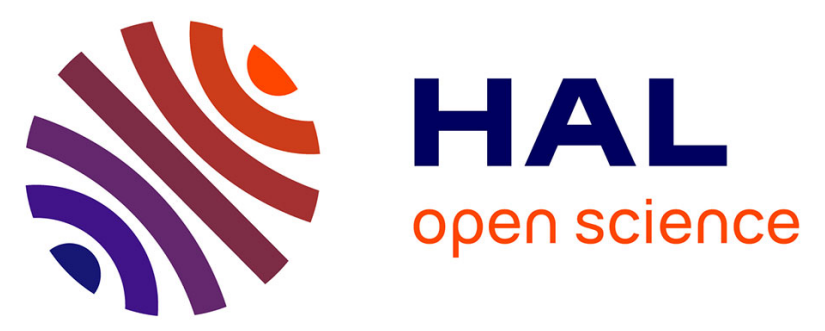

\title{
Engendering health sector responses to sexual violence and HIV in Kenya: Results of a qualitative study
}

Nduku Kilonzo, Miriam Taegtmeyer, Catherine Molyneux, Josephine Kibaru, Virginia Kimonji, Sally Theobald

\section{- To cite this version:}

Nduku Kilonzo, Miriam Taegtmeyer, Catherine Molyneux, Josephine Kibaru, Virginia Kimonji, et al.. Engendering health sector responses to sexual violence and HIV in Kenya: Results of a qualitative study. AIDS Care, 2008, 20 (02), pp.188-190. 10.1080/09540120701473849 . hal-00513428

\section{HAL Id: hal-00513428 https://hal.science/hal-00513428}

Submitted on 1 Sep 2010

HAL is a multi-disciplinary open access archive for the deposit and dissemination of scientific research documents, whether they are published or not. The documents may come from teaching and research institutions in France or abroad, or from public or private research centers.
L'archive ouverte pluridisciplinaire HAL, est destinée au dépôt et à la diffusion de documents scientifiques de niveau recherche, publiés ou non, émanant des établissements d'enseignement et de recherche français ou étrangers, des laboratoires publics ou privés. 

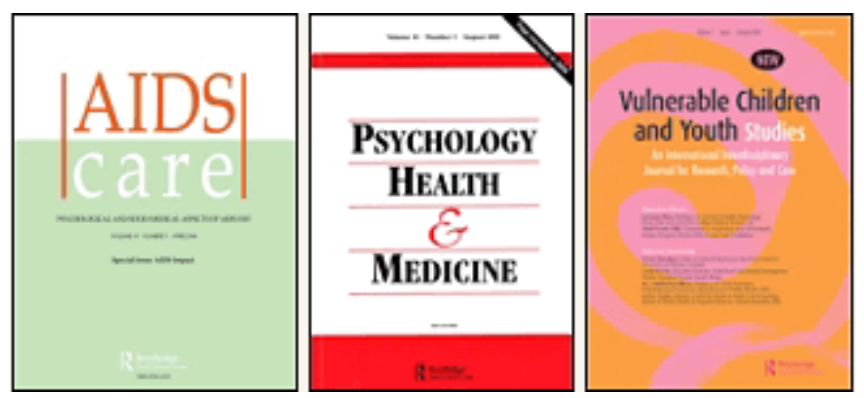

\section{Engendering health sector responses to sexual violence and HIV in Kenya: Results of a qualitative study}

\begin{tabular}{|r|l|}
\hline Journal: & $\begin{array}{l}\text { AIDS Care - Psychology, Health \& Medicine - Vulnerable Children } \\
\text { and Youth Studies }\end{array}$ \\
\hline Manuscript ID: & AC-2007-05-0232 \\
\hline Journal Selection: & AIDS Care \\
\hline Keywords: & $\begin{array}{l}\text { sexual violence, post rape care, HIV, post exposure prophylaxis, } \\
\text { Kenya }\end{array}$ \\
\hline
\end{tabular}

\section{(5) ScholaroNE \\ Manuscript Central}




\section{Engendering health sector responses to sexual violence and} HIV in Kenya: Results of a qualitative study

In Kenya many people who have been affected by sexual violence turn to the health sector for clinical treatment and preventive therapies. This interface provides a vital opportunity to impact on the dual epidemics of HIV and sexual violence. Despite this, the uptake of existing post-rape care services was low when the study was commenced and health care providers feel ill-prepared to deal with the consequences of sexual violence. A qualitative study was conducted to better understand the reasons for the low uptake of services and to establish perceptions of sexual violence in Kenya. Thirty-four key informants were interviewed and sixteen focus group discussions with women and men were held in three districts in Kenya. Blurred boundaries between forced and consensual sex emerged. Important implications for the delivery of HIV PEP after sexual violence include the need for gender aware patient centred training for health providers and for HIV PEP interventions to strengthen on-going HIV prevention counselling efforts. Further research needs to determine the feasibility of on-going risk reduction measures in the context of PEP delivery.

Key words: Sexual violence, Rape, HIV, Post-rape care/services, Post Exposure Prophylaxis, Kenya 


\section{Engendering health sector responses to sexual violence and}

\section{HIV in Kenya: Results of a qualitative study}

\section{Gender, sexual violence and HIV}

Vulnerability to sexual violence and associated risk of HIV infection are often rooted in unequal gender power relations. Published literature reporting sexual violence in Kenya is limited (Erulkar, 2004; Speight et al., 2006; Lalor, 2004). The 2003 Kenya Demographic Health Survey showed that $13 \%$ women aged $20-29$ years had experienced sexual violence in the year preceding the study (Government of Kenya, 2004).

Vulnerability to HIV infection in the context of sexual violence may be higher than during consensual sex because of genital trauma, multiple perpetrators and/or concomitant STIs (Royce et al., 1997). HIV Post-Exposure Prophylaxis (PEP) can reduce the risk of HIV infection following sexual violence (Cardo et al., 1997). HIV/PEP is a 28-day regime of a combination of anti-retroviral drugs given to HIV negative persons following potential exposure to HIV (CDC, 1998).

\section{The need to engender responses to sexual violence in the health sector}

Analyses that locate institutional responses to sexual violence and HIV in gendered frameworks are limited. Despite the pervasive nature of sexual violence, training in many countries does not adequately prepare service providers to deal with the psychosocial or health consequences of violence (Garcia-Moreno, 2002). Literature 
that explicitly attempts to analyse the ways in which gender relations shape access, delivery and up-take of specialised health care services is lacking.

\section{Methods}

A situational analysis on perceptions of rape and post-rape care services available in Kenya was conducted in three (3) districts (Thika, Malindi and Nairobi) in 2004. The key objectives were to establish the perceptions of sexual violence in Kenya and to inform the development of a strategy for implementation of post-rape care services in the three district hospitals.

Qualitative methods were used due to the sensitive nature of HIV and sexual violence, the need to respond flexibly to participant views, norms and values and the requirement to better understand complex social interactions (Pope \& Mays, 1995). Given the potential for emotional stress in study participants, practising HIV counsellors were trained as research assistants. All study participants gave informed consent to voluntarily participate in the study.

\section{District and participant selection}

Sixteen focus group discussions (FGDs) were conducted. These included one group for each category (adult women, adolescent women, adolescent men and adult men) in Thika and Malindi. In Nairobi there were two groups of each category. Participants were community members resident within the vicinity of VCT sites, selected to reflect those who might access, or influence access to services. Thirty-four individual key 
informant interviews (19 male and 15 female) were also undertaken as follows: twelve participants from health care facilities, six counsellors from VCT sites, five from religious institutions, six from advocacy and legal organizations and five police officers.

\section{Analysis}

Immediate debriefing and transcription of interviews enhanced the trustworthiness of the approach by keeping research teams aware of emerging gaps and biases. Content analysis was conducted and key emergent themes were identified and triangulation of these undertaken through comparing and contrasting data from the different districts and the different groups interviewed (Spencer et al., 2003).

\section{$\underline{\text { Results }}$}

\section{Blurred boundaries between forced, coercive and consensual sex}

An important theme from individual and group interviews with community members were blurred boundaries between forced, coerced and consensual sex. Descriptions of what constitutes consent, coercion or force in both marital and non-marital relations suggested a lack of clarity. For example:

"Now to me, if you are married and... if I do it by force, it is not rape, it is called, we can call it something else, maybe like an argument, or something, but not rape” (Adult male, Malindi) 
The complexities of consent (or lack of it) are also reflected in the women's perceived inability to assertively say no to sex. For example, one male adolescent in Nairobi said that "African girls say no when they mean yes", and a female adolescent in Thika explained that some girls do not say "no" clearly enough. This apparent lack of clarity in whether or not girls want to have sex was the explanation given for 'using force sometimes' by adolescents.

Existing services, perceptions of sexual interactions and implications for service uptake

All participants clearly identified rape as a risk factor for HIV infection. Adolescent and adult women and men were asked; 'What services should be provided for survivors?'. There was no awareness of the existence and use of PEP to prevent HIV from the group discussions and there was invariably interest and scepticism when moderators prompted for knowledge. Questions raised included; 'how does it work?'; 'does it really work?'; 'are you sure of what you are saying?'.

Service providers were also asked about constraints faced in the provision of services. Infrastructural constraints cited were the lack of standards, and limited financial, technical and human resource capacities. In addition, eight clinicians and two police officers expressed difficulties in discussing sexual violence with both survivors and providers. For instance, a female clinical officer from Malindi described the physical examination as, "A difficult experience...even just talking about it to get the details..." 
A police officer in Malindi noted that "Questions seem to be intimidative to them... you can't ask some things like from the old woman... many are just quiet"

\section{Discussion}

Gender norms and values in the Kenyan context clearly shape vulnerability to, understandings of and responses to sexual violence. While many responses to sexual violence and HIV are needed outside of the health sector, the health sector sits squarely at the nexus of prevention and care for both sexual violence and HIV, and is considered here.

The blurred boundaries between coercive, forced and consensual sex, present challenges for the uptake of health care after sexual violence. This is exacerbated by the difficulties that health providers face in discussing sexual violence and supporting survivor communication. This leads to lost opportunities including: insufficient assessment for sexual violence and HIV risk: failure to develop targeted HIV risk reduction strategies where future occurrences are likely: inability to evaluate and appropriately address the individualised vulnerabilities of survivors: and inadequate support for uptake and adherence to PEP. The latter is particularly critical as uptake of HIV testing and PEP potentially places HIV positive female survivors at increased risk of inter-personal violence (Maman et al., 2002). Compliance to recommendations for abstinence or protected sex for at least three months after exposure may pose further threats for both PEP uptake and adherence. 
The health sector needs to take urgent action at two levels: (1) delivering community awareness campaigns on the availability of PEP, and (2) offering provider training on patient centred and gender aware approaches to discussing sexual violence, counselling and testing and PEP provision and adherence. An understanding of how gender shapes women and men's vulnerability, experience and responses to sexual violence needs to underpin these actions. The research was limited in that it did not explore community or provider perceptions on the feasibility of on-going risk reduction measures in the context of PEP delivery. This needs further investigation.

\section{Conclusion}

Engendering service delivery requires health provider training in delivery of post rape care services. Training should address how gender can shape survivors' ability to control their vulnerability to future occurrences of sexual violence, present for post rape care and adhere to PEP medication. The delivery of PEP provides opportunities for strengthening broader HIV prevention by utilising the moment of presentation by survivors as a portal for on-going HIV risk reduction counselling. However, the success of such interventions lies in designing counselling and treatment protocols that acknowledge risks posed by sexual violence in the context of blurred boundaries between forced and consensual sex.

\section{Ethics}

Ethical approval was acquired from the Kenyatta National Hospital and the Liverpool School of Tropical Medicine Ethical Review Boards. 


\section{Acknowledgements}

The authors would like to thank all the participants of FGDs and the individual interviews. The HIV/AIDS Knowledge Programme, Liverpool School of Tropical Medicine (LSTM) is a collaborative programme funded by DFID (Department for International Development, UK) to develop 'knowledge for action' in HIV/AIDS prevention and care and funded the situational analysis for 6 months. Liverpool VCT Kenya, through core funding and with support from TROCAIRE and DfID funded all other aspects of the study. The researchers were independent from funders.

Conflict of Interest: The authors have no conflict of interest. 


\section{Reference List}

Cardo, D. M., Culver, D. H., Ciesielski, C. A., Srivastava, P. U., Marcus, R., Abiteboul, D., Heptonstall, J., Ippolito, G., Lot, F., McKibben, P. S., \& Bell, D. M. (1997). A case-control study of HIV seroconversion in health care workers after percutaneous exposure. Centers for Disease Control and Prevention Needlestick Surveillance Group. New England Journal of Medicine, 337, 1485-1490.

Centre for Disease Prevention and Control. (1998). Management of possible sexual, injecting-drug-use, or other non-occupational exposure to HIV, including considerations related to Antiretroviral Therapy. Public Health Service Statement. $M M W R, 47,1-14$.

Erulkar, A. (2004). The Experience of Sexual Coercion Among Young People in Kenya. International Family Planning Perspective, 30, 182-189.

Garcia-Moreno, C. (2002). Dilemmas and opportunities for an appropriate healthservice response to violence against women. Lancet, 359, 1509-1514.

Government of Kenya, Central Bureau of Statistics (2004). Kenya Demographic Health Survey 2003. 2nd Ed., Calverton: Maryland.

Lalor, K. (2004). Child sexual abuse in Tanzania and Kenya. Child Abuse \& Neglect, $28,833-844$. 
Maman, S., Mbwambo, J. K., Hogan, N. M., Kilonzo, G. P., Campbell, J. C., Weiss, E., \& Sweat, M. D. (2002). HIV-positive women report more lifetime partner violence: findings from a voluntary counseling and testing clinic in Dar es Salaam, Tanzania. American Journal of Public Health, 92, 1331-1337.

Pope, C., \& Mays, N. (1995). Qualitative Research: Reaching the parts other methods cannot reach: an introduction to qualitative methods in health and health services research. British Medical Journal, 311, 42-45.

Royce, R. A., Sena, A., Cates, W., \& Cohen, M. S. (1997). Sexual Transmission of HIV. The New England Journal of Medicine, 336, 1072-1078.

Speight, C. G., Klufio, A., Kilonzo, N., Mbugua, C., Kuria, E., Bunn, J. E., \& Taegtmeyer, M. (2006). Piloting post-exposure prophylaxis in Kenya raises specific concerns for the management of childhood rape. Transactions of the Royal Society of Tropical Medicine and Hygiene, 100, 14-18.

Spencer, L., Ritchie, J., \& O’Connor, W. (2003) 'Analysis: Practices, Principles and Processes' in Eds. J. Ritchie and J. Lewis. Qualitative Research Practice: A guide for Social Science Students and Researchers. London: SAGE Publications

\section{1}

http://mc.manuscriptcentral.com/ac-phm-vcy 
